\title{
TRADUÇÃO CRIATIVA, DIAGRAMA \\ E CÁLCULO ICÔNICO
}

João Queiroz

\author{
"O diagrama representa uma forma \\ definida de relação" \\ "O raciocínio diagramático é o único tipo realmente \\ fértil de raciocínio"
}

C.S. Peirce

- (CAMPOS, Haroldo de. $O$ Arco-íris branco. São Paulo: Imago, 1997: 52; ver também: PAZ, O. e CAMPOS, Haroldo de. Transblanco. Rio de Janeiro: Editora Guanabara, 1986: 89)

"(RANSDELL, J. “On Peirce's conception of the iconic sign". In: SEBEOK, T., BOUISSAC, P., HERZFELD, M. \& POSNER, R. (Eds). Iconicity: Essays on the Nature of Culture. The Netherlands: John Benjamins Publishing Co., 1986.)

- (PEIRCE, C.S. Writings of Charles S. Peirce. M. Fisch, E. Moore, and C. Kloesel (Eds.). Bloomington: Indiana University Press, v. 3, 1982: 62-65.)

- (MORRIS, Charles W. Writings on the General Theory of Signs. Den Haag: Mouton, 1971.)

* (ver também: ZEMAN, Jay. "The esthetic sign in Peirce's semiotic" In: Semiotica, v.19, n.3/4, 1977: 241-258; Pignatari, Décio. Semiótica \& Literatura. São Paulo: Ateliê Editorial, 2004.)

• (ver STJERNFELT, F. Diagrammatology: an investigation on the borderlines of phenomenology, ontology and semiotics. New York: Springer, 2007.)

\section{Introdução}

O poeta e ensaísta Haroldo de Campos define tradução criativa, ou transcriação, no "avesso da chamada tradução literal", como prática isomórfica (ou paramórfica):

será sempre criação paralela, autônoma, porém recíproca. [...] Uma tradução isomórfica seria, por definição, uma tradução icônica. Lê-se no meu ensaio [Da Tradução como Criação e como Crítica]: "Numa tradução dessa natureza não se traduz apenas o significado, traduz-se o próprio signo, ou seja, sua fisicalidade, sua materialidade mesma (propriedades sonoras, de imagética visual, enfim tudo aquilo que forma, segundo Charles Morris, a iconicidade do signo estético, entendido por signo icônico aquele que é de certa maneira similar aquilo que ele denota"*

Tal identificação (tradução criativa = tradução icônica) tem muitas consequências. O ícone é um tipo de signo indissoluvelmente ligado a seu objeto, um análogo de sua própria constituição, formal, estrutural, ou material. ${ }^{*}$ Ele apresenta diretamente seu objeto através de sua forma, estrutura ou constituição material. Sabemos, ao menos desde Charles Morris, ' que o signo estético é de natureza predominantemente icônica. ${ }^{*}$ Mas as ideias de analogia e similaridade, centrais à tese de Haroldo, enfaticamente associadas aos ícones, podem ser desenvolvidas em novas direçôes. Quando um critério operacional é adotado, o ícone é definido como qualquer coisa cuja manipulação pode revelar mais informação sobre seu objeto, e a álgebra, a sintaxe, os grafos, e as formalizações de todos os tipos devem ser reconhecidas como ícones: 
A chave da iconicidade não é uma semelhança percebida entre o signo e o que ele significa mas, mais do que isso, a possibilidade de fazer novas descobertas sobre o objeto através da observação das características do signo, em si-mesmo.

Tal definiçãa é considerada uma destrivialização da noção de que o ícone é fundamentalmente uma relação de similaridade. Os diagramas são ícones associados à descoberta de relações, como veremos.

\section{Definição}

São dois os trabalhos* que fornecem a Haroldo de Campos os principais subsídios que lhe permitem postular como possibilidade da tradução poética, "em um giro dialético”, sua intraduzibilidade por princípio, relacionados à concreção e materialidade dos processos icônicos.

Sumariamente, relações isomórficas, de "parentesco", percebidas entre diversos níveis de organização (e.g. fonético-semântico, sintático-morfológico), e descritas como "equações verbais", são "recriadas" do signo-fonte ao signo-alvo. ${ }^{1}$ Esta "transcriação", como Haroldo sugere, baseia-se na recriacão de relaçôes entre relações de similitude e contraste, uma operação que podemos descrever como diagramática.

Os diagramas são tipos especiais de ícones. Tão logo um ícone seja examinado como consistindo de partes inter-relacionadas, e uma vez que estas relações estejam sujeitas a modificações experimentais reguladas por normas e leis, estamos operando com diagramas. O ícone prototípico é descrito como a manipulação de uma figura geométrica para observação de um teorema. Mas a ideia é bastante geral. Um ícone pode ser caracterizado como um signo que revela informação através de algum procedimento acompanhado de observação. Já em 1880, Peirce (“A álgebra da lógica”) indica a natureza icônica do silogismo, com implicações evidentes para a categoria geral do ícone:

\footnotetext{
${ }^{1}$ Sobre este conceito, afirma Jakobson: "Em poesia, as equaçôes verbais são elevadas à categoria de princípio construtivo do texto. As categorias sintáticas e morfológicas, as raízes, os afixos, os fonemas e seus componentes (traços distintivos) - em suma, todos os constituintes do código verbal - são confrontados, justapostos, colocados em relação de contiguidade de acordo com o princípio de similaridade e de contraste, e transmitem assim uma significação própria” (JAKOBSON, R. Linguística e Comunicação, São Paulo: Editora Cultrix, 1969: 72; ênfase adicionada).
}

- (HOOKWAY, C. Truth, Rationality, and Pragmatism: Themes from Peirce. Oxford: Oxford University Press, 2002: 102.)

•(STJERNFELT, F. “Diagrams as centerpiece in a Peircean epistemology", Transactions of the Charles S. Peirce Society, v.36, n.3, 2000: 357-92)

" (JAKOBSON, R. “On Linguist Aspects of Translation". In: VENUTI, Lawrence (Ed.). The Translation Studies Reader. London \& New York: Routledge, 2000 [1959]: 113-118; BENJAMIN, Walter. "A Tarefa do Tradutor" [Die Aufgabe des Übersetzers] Gesammelte Schriften, IV.1, 1923: 9-21.) 
(CP 3.363; Peirce, C.S. The Collected Papers of Charles S. Peirce. C. Hartshorne, C., Weiss, P. \& Burks, A.W. (Eds.). Cambridge: Harvard University Press, 1931-1966.)

- (MS 318: 81, PEIRCE, C.S. Manuscripts in the Houghton Library of Harvard University. ROBIN, Richard (Ed.), Annotated Catalogue of the Papers of Charles S. Peirce. Amherst: University of Massachusetts Press, 1967)

" (QUEIROZ, J. Semiose Segundo Peirce. São Paulo: EDUC, 2004: 80.)

'(CP 2.299, PEIRCE, C.S. The Collected Papers of Charles S. Peirce. C. Hartshorne, C., Weiss, P. \& Burks, A.W. (Eds.). Cambridge: Harvard University Press, 1931-966.)

- JOHANSEN, D. Dialogic Semiosis. Indiana: Indiana University Press, 1993: 99.)

- (FARIAS, P. e QUEIROZ, J. "Images, diagrams, and metaphors: hypoicons in the context of Peirce's sixty-six fold classification of signs". Semiotica v.162, n. 1/4, 2006: 287-308.)
[...] Todo raciocínio dedutivo, mesmo o silogismo simples, envolve um elemento de observação; a saber, a dedução consiste em construir um ícone ou diagrama em que as relações de suas partes devem apresentar uma analogia completa com aquelas das partes do objeto do raciocínio, da experimentação sobre esta imagem na imaginação e da observação do resultado, assim sendo que descubra as relaçôes desapercebidas e escondidas entre as partes

Como uma transformação controlada, uma tradução baseia-se nas leis que regulam cada nível de organização, de um lado, e nas relações inter-níveis, de outro.

\section{Semiose, ícones e diagramas}

Para Peirce, a semiose ("ação do signo") é um fenômeno irredutivelmente triádico (relação indecomponível de três termos) que relaciona um Signo $(\mathrm{S})$ a seu Objeto $(\mathrm{O})$, para um Interpretante (I), ou efeito sobre um intérprete -

o signo "é determinado pelo objeto relativamente ao interpretante, e determina o interpretante em referência ao objeto, de tal modo a produzir o interpretante a ser determinado pelo objeto através da mediação do signo".

Para explicar a variedade morfológica de eventos que atuam sobre os intérpretes, Peirce sugeriu uma divisão bastante conhecida - signos icônicos, indexicais e simbólicos. ${ }^{*}$ Eles, aproximadamente, correspondem a relações de similaridade, de contiguidade física, e de lei que podem ser estabelecidas entre um Signo e seu Objeto.

Ícones são Signos que estão para seus Objetos através de similaridade, sem consideração por qualquer conexão espaço-temporal que possam ter com objetos existentes. ${ }^{*}$ Se $S$ é um signo de $\mathrm{O}$ em virtude de uma certa qualidade que $S$ e $\mathrm{O}$ compartilham, então $\mathrm{S}$ é um ícone de $\mathrm{O}$. Se $\mathrm{S}$ é um ícone de $\mathrm{O}$, comunica, para $\mathrm{I}$, uma qualidade de $\mathrm{O}$.

O diagrama é um tipo de ícone. Os diagramas são "a principal, senão única, forma de adquirirmos novo conhecimento sobre relaçôes". Na tipologia dos ícones, o diagrama forma a segunda sub-categoria, entre três tipos de hipoícones - imagens, diagramas, metáforas. $\mathrm{O}$ diagrama representa, através das relações entre suas partes, as relaçôes que constituem as partes relacionadas do objeto que representa. O objeto do diagrama é sempre uma relação, e as partes relacionadas do diagrama representam as relações que constituem o objeto representado. Diferente da imagem, que relaciona 
qualidades superficiais, o diagrama é um arranjo de partes relacionadas, e seu objeto só pode ser uma relação análoga.

Os índices e os símbolos são bastante conhecidos. Se $\mathrm{S}$ é um Signo de $\mathrm{O}$ em razão de "conexão física direta" com $\mathrm{O}$, então ele é índice de O. Neste caso, $\mathrm{S}$ é realmente determinado por $\mathrm{O}$ de tal modo que ambos devem existir como eventos. A noção de co-variação espaço-temporal é a propriedade mais mencionada dos processos indexicais. Os exemplos incluem de um "pronome demonstrativo ou relativo", que "força a atenção para um objeto particular, sem descrevê-lo", a sintomas físicos de doenças, fotografias, barômetros e termômetros. O símbolo, por sua vez, é um Signo que está relacionado com seu Objeto em virtude de uma lei ou norma. Símbolos são capazes de representar "coisas" que não precisam existir de fato, ou que existem mas não estão perceptualmente manifestas, que jamais existiram, ou, ainda, entidades que não podem sequer ser intuitivamente concebidas ("estranhos" objetos das lógicas não clássicas, criaturas imaginárias, etc). Uma importante propriedade é que restrições impostas à presença espaço-temporal do Objeto representado pelo índice, que ele conecta co-incidentemente, não tem lugar em processos simbólicos. Um símbolo é "um signo que é constituído meramente, ou principalmente, pelo fato de que é usado ou entendido como tal, seja natural ou convencional o hábito, e sem observar os motivos que originalmente governaram sua seleção".

\section{4. Ícone e tradução icônica}

A qualidade representativa do ícone é aquilo que Peirce descreve como uma "pura primeiridade categórica", que é uma qualidade que ele possui em si mesmo, independente de qualquer outra coisa. Um caráter interno, "que pertence a ele, em si mesmo, como um objeto sensível, e que ele possuiria de qualquer forma, havendo ou não um objeto na natureza a que ele se assemelhe, ainda que jamais tenha sido interpretado como um signo". Mas Peirce admitiu a vagueza desta definição. São muitos os perigos relacionados à noção de similaridade, especialmente sua trivilialização como identidade e sua psicologização como referindo-se a impressões de semelhança. Mas as desvantagens são superadas pela destrivialização baseada na noção operacional. No "Syllabus", a similaridade é assim definida: "uma propriedade distintiva do ícone é que, através de sua observa-
- (CP 1.372; PEIRCE, C.S. The Collected Papers of Charles S. Peirce. op. cit.)

"(CP 1.369; Peirce, C.S. The Collected Papers of Charles S. Peirce. C. Hartshorne, C., Weiss, P. \& Burks, A.W. (Eds.). Cambridge: Harvard University Press, 1931-1966)

(CP 2.307; PEIRCE, C.S. The Collected Papers of Charles S. Peirce. op. cit.)

- (CP 4.447; PEIRCE, C.S. The Collected Papers of Charles S. Peirce. op. cit.) 
( (CP 2.279; PEIRCE, C.S. The Collected Papers of Charles S. Peirce. op. cit.)

* (CP 2.282; PEIRCE, C.S. The Collected Papers of Charles S. Peirce. op. cit.)

( (lbidem.)

• (CP 4.513; PEIRCE, C.S. The Collected Papers of Charles S. Peirce. op. cit.) ção direta, outras verdades considerando seu objeto podem ser descobertas além daquelas satisfeitas na determinação de sua construção". Esta propriedade é uma elaboração operacional do conceito de similaridade. $\mathrm{O}$ ícone não é somente o único tipo de signo envolvendo uma apresentação direta de qualidades que pertencem a seu objeto; ele é também - e isto equivale ao mesmo - o único signo através do qual, por sua observação direta, se pode descobrir algo sobre seu objeto. Esta definição distingue o ícone de qualquer psicologismo: não importa se signo e objeto, à primeira vista, pareçam similares; o teste decisivo de iconicidade está na possibilidade de manipulá-lo para que uma nova informação apareça.

Paralelamente, as qualidades materiais que pertencem ao signo, como um objeto sensível, enfatizam o aspecto concreto da semiose. Este aspecto distingue o signo icônico. Poderíamos dizer, a la Wittgenstein, que o ícone mostra seu significado através das formas materiais de sua expressão. Mas há outro elemento na definição que deve ser cuidadosamente notado, e que é fundamental na caracterização do diagrama. Um exemplo tomado da álgebra é esclarecedor: "De fato, toda equação algébrica é um ícone, desde que exiba, por meio de seus signos algébricos (que não são eles mesmos ícones) as relaçôes das quantidades envolvidas. "* Vamos encontrar esta propriedade particular no fenômeno que nos interessa, uma vez que signos verbais não são predominantemente icônicos. Como assinalei, se um signo é contemplado como um todo consistindo de partes inter-relacionadas, e se estas relações estão sujeitas a mudanças experimentais controladas por leis, estamos operando com um diagrama. Peirce afirma: "De qualquer modo, um diagrama é claramente, em todo o caso, um signo de uma Coleção, ou Plural, ordenado, ou, mais exatamente, da Pluraridade ou Multitude ordenada". O diagrama é um esquema de seu objeto em termos de relaçóes entre suas partes, mas o que o torna apto à experimentação, é o fato de que ele é construído através de relações inteligíveis - "Um diagrama é, principalmente, um ícone, e um ícone de relaçôes inteligíveis". * O diagrama não somente representa os correlatos relacionados, mas também e muito mais definitivamente, representa as relações entre eles, como objetos do ícone.

O que pode ser definido como "fisicalidade do signo" (fonte e alvo, em uma tradução) tem portanto a natureza de uma relação. Tal propriedade é muito claramente manifesta nas operaçôes cria- 
tivas de tradução, conforme assinala Haroldo. As "transcriações" baseiam-se em relações (paramórficas) entre partes relacionadas. $\mathrm{O}$ objeto da tradução é uma relação. Seu propósito é revelar relações (paramórficas consideradas relevantes) do signo-fonte.

Aproveito para exemplificar com a tradução de um trecho de John Donne, feito por Augusto de Campos, ${ }^{*}$ do poema The Expiration (A expiração), que o tradutor faz acompanhar de uma precisa metalinguagem sobre a complexa "urdidura" diagramática (fônica, gráfica, semântica) que deve revelar-recriar em língua portuguesa:

em nível semântico

o poema desenvolve a imagem-título tomada no duplo sentido

de "respirar" e de "morrer" e transposta ao sentimento da separação amorosa: o amante convida a amada a expirar no ar o beijo final (através da expiração as duas almas fantasmas deixarão os corpos) e se propóe matar o seu amor com uma simples palavra: "vai" (go.) estopim da separação e da morte

pede, por fim, que essa palavra ressoe nele próprio o que significará morrer duas vezes (being double dead) por "ir" e "mandar ir" (going and bidding go)

essa equação conceitual encontra eco e ícone nas camadas fônicas e gráficas do poema por um artifício específico:

a reduplicação q pode aqui ocorrer com morfemas (so, so / go; go) com fonemas próximos em pares aliterativos (last lamenting / sucks two souls turn thou / turn this leave to love / word work) ou mesmo com grafemas repetidos (we owe) e com toda uma cadeia de fonemas e grafemas redobrados especialmente em torno de $b / d / g$ 
não falo das naturais reduplicações

ortográficas (como mee

na grafia antiga)

embora até mesmo estas

pareçam contaminar-se

de virtualidades icônicas

depois do feed back provocado pela última linha aquela onde incide a mais densa carga

de reduplicações especulares.

aqui vai ela numa transcrição gráfica

que visa a acentuar os agentes iconopaicos:

\section{being double dead, going and bidding, go}

a dupla morte está gravada e grafada nesta linha em $b b$ e $d d$ e $g g$

(em minha transcrição começo com minúscula e uso tipos em que o $b$ e o $d$ são formas-espelho para obter o máximo de rendimento icônico)

das palavras começadas por consoantes

(q são todas menos uma)

duas se iniciam por $b$

duas por $d$

e duas por $g$.

dentre as começadas por $d$ e $g$

duas (dead e going)

começam e terminam pela mesma consoante.

e as duas últimas palavras (bidding, go)

se ligam pela consoante $g$.

a linha toda é percorrida

por uma série de espalhamentos

entre $b$ e $d$

(na área fônica

devem-se computar ainda

as sucessōes de sons nasais

(being / going / and / bidding)

é por assim dizer

com esses íons e elétrons

intravocabulares

que donne cria a corrente magnética

de microssons e microimagens

do verso final

forma pregnante

que realimenta todo o poema

Ainda Augusto de Campos:* 
mas como experienciar

a fundo a criação de um poema

sem desvendar o véu da sua oculta

urdidura subjacente?

O objeto "desvendado" é uma relação selecionada pelo estoque de alternativas disponíveis (e descobertas) por Augusto. A recriação da equação verbal é uma operação controlada (legaliforme, e simbólica) para revelar relações de paramorfismo entre níveis de organização do signo-fonte. A ideia é a mesma: uma manipulação diagramática é feita para descobrir propriedades relacionais. A recriação, em português, dos paramorfismos que operam entre a "densidade fônica e gráfica do original”, no poema de Donne, corresponde a recriação de uma "coleção ordenada" de propriedades (fônicas, gráficas), e aproximadas (através de similitude e contraste), para reverberar semanticamente no signo-alvo. (A relevância é deslocada para a relação entre as partes do objeto, uma coleção ordenada de propriedades características.)

O resultado:*

So, so, leave off this last lamenting kiss, which sucks two souls, and vapours both away, turn thou ghost that way, and let me turn this, and let our selves benight our happy day; we ask'd none leave to love; nor will we owe any, so cheap a death, as saying, Go;

go; and if that word have not quite killed thee, ease me with death, by bidding me go too. $\mathrm{Oh}$, if it have, let my word work on me, and a just office on a murderer do.

Except it bee too late, to kill me so, being double dead, going, and bidding, go.

Susta ao beijo final a fome de beijar que as duas almas suga e a ambas evapora, e, fantasmas do amor, fantasiados de ar, façamos nós a noite em nosso dia agora; amar não custou nada, nada vai custar a morte que eu te dou, dizendo: - Vai embora!

- Vai! Se este som mortal não te matar por fim, dá-me tal morte então, mandando-me partir. Ai! Se matar, que som igual ressoe em mim 
E ao matador que eu fui também o mate assim,

Se não matar demais, por me fazer sentir

dobrada a morte e dor, indo e mandando ir.

\section{Implicações}

Se o ícone é o único tipo de signo envolvendo uma apresentação direta das qualidades que pertencem a seu objeto, um teste decisivo sobre a iconicidade está na possibilidade de, ao manipulá-lo, ter revelado uma nova informação sobre o objeto. Com o critério operacional do ícone, podemos apreciar o papel dos diagramas. Sabemos que há, nos ícones, uma concentração nos aspectos de concrȩãa do processo semiótico, relacionados à materialidade do signo. Que esta seja uma destacada propriedade associada aos ícones, não há novidade sobre isso, e este não foi meu propósito aqui. $\mathrm{O}$ que me parece mais sugestivo, e pode conduzir as especulações de Haroldo de Campos em uma direção ainda não explorada, é outra questão: o papel fundamental exercido por operações diagramáticas. Aquilo que é revelado, e descoberto, nas "traduções criativas ou transcriaçōes", são as relaçōes entre as partes que constituem o signo (signo-fonte e signo-alvo), aquelas que operam entre diversos níveis ou camadas de organização - as estruturas relacionais, e paramórficas, entre componentes que atuam em diferentes níveis. É facil supor que qualquer "recriação de equaçōes verbais" deve considerar restriçóes impostas por leis que atuam em (e entre) diversos níveis, nos signos-fonte e alvo - e.g., fonético, morfológico, sintático, semântico, pragmático e histórico, uma vez o processo envolve a recriação de componentes contexto-dependentes.

A recriação de relações de paramorfismos deve revelar alguma informação sobre a "equação original", que pode ser descrita como um conjunto de restriçôes que operam entre diversos níveis, no signo-fonte. Em outros termos, a recriação paramórfica equivale a transformação controlada de relações percebidas como análogas, entre diversos níveis de descrição do signo-fonte, e selecionadas através do estoque de relações disponíveis e descobertas no sistema-alvo. Conforme esta perspectiva, a tradução corresponde à recriação de relações que operam em um sistema multi-níveis de restriçōes, descobertas ou "selecionadas" (em termos de materiais criados, disponibilizados, escolhidos) pelo signo-alvo. As restrições são reveladas como diagramas observados no signo-alvo. A tradu- 
ção é a descoberta de uma relação, "urdidura subjacente", * experimentação diagramática e "cálculo icônico".

O status atribuido à tradução criativa como tarefa de descoberta baseia-se em outra noção subsidiária, podendo conduzir-nos a consequências ainda inexploradas. As ideias gerais rapidamente esboçadas aqui apontam para uma epistemologia diagramática da tradução, com consequências (eu creio) em uma agenda de investigação que deve ser cuidadosamente detalhada, exaustivamente exemplificada e testada. Idealmente, seus resultados podem ser comparados com formas diversas de inferência criativa, ou abdutiva, em operaçôes tipicamente diagramáticas, em diversas áreas (e.g., música, design, lógica, matemática etc).

\section{João Queiroz}

É professor do Instituto de Artes e Design e do Programa de Pós-Graduação em Comunicação, da Universidade Federal de Juiz de Fora (UFJF). É editor do International Journal of Signs and Semiotic Systems [www.igi-global.com/ijsss], autor, organizador e co-organizador de diversos artigos e livros entre os quais: Genes, Information, Semiosis (2009, Tartu University Press), Artificial Cognition Systems (2007, Idea Group) Semiotics and Intelligent Systems Development (2007, Idea Group), Semiose Segundo Peirce (2004, Educ).

\section{Resumo}

O ícone é operacionalmente definido como um signo cuja manipulação permite, por observação direta de suas propriedades intrínsecas, a descoberta de alguma informação sobre seu objeto. Esta definição representa uma destrivialização da noção do ícone como um análogo do objeto representado. Vou explorar aqui a noção de tradução icônica, que Haroldo de Campos relaciona à tradução criati$v a$, em uma nova direção, baseado em um critério operacional que associa os ícones aos diagramas, que são signos icônicos de relação. Tão logo um ícone seja observado como algo consistindo de partes inter-relacionadas, e uma vez que as relações estejam sujeitas a mudanças experimentais baseadas em leis, estamos operando com diagramas. Trata-se de um argumento conhecido que a tradução criativa recria relaçôes de isomorfismos (ou paramorfismos) entre diversos níveis de descrição do signo traduzido. Esta ideia aqui é subsidiada pelo conceito operacional do ícone, capaz de revelar a forma definida de uma relação. Exemplifico, ao final, minha argu-

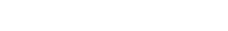


mentação exibindo um caso notável de tradução de John Donne, por Augusto de Campos.

Key words: translation; diagram; iconic calculation; Peirce.

Palabras clave: traducción; diagramas; cálculo icónico; Peirce.
Recebido em

$31 / 07 / 2010$

Aprovado em 30/09/2010

\section{Abstract}

The icon is operationally defined as a sign whose manipulation reveals, by direct observation of its intrinsic property, some information on its object. This definition represents a detrivialization of the concept of icon as a similar entity. Here we explore Haroldo de Campos' concept of "iconic translation", and we develop this concept in a new direction, based on an operational criterion that associates the icon to diagrams, iconic signs of relationship. It is a well-known argument that creative translation recreates isomorphic (or paramorphic) relations between different levels of description (or organization) of the translated sign. This idea is framed here by an operational concept of icon capable of revealing a definite form of a relationship. In the end, I exemplify my argument showing a case of translation of John Donne, by Augusto de Campos.

\section{Resumen}

El icono se define operacionalmente como un signo cuya manipulación permite, a través de la observación directa de sus propiedades intrínsecas, el descubrimiento de alguna información acerca de su objeto. Esta definición representa una destrivializacion de la noción del icono como un análogo del objeto representado. Voy a estudiar aquí la noción de traducción icónica, que Haroldo de Campos relaciona a la traducción creativa, en una nueva dirección, con base en un criterio operativo que asocia los iconos a los diagramas, que son signos icónicos de relación. Tan pronto el icono sea observado como algo compuesto de partes interrelacionadas, y una vez que las relaciones estén sujetas a cambios experimentales basados en leyes, estamos trabajando con diagramas. Se trata de un conocido argumento que la traducción creativa recrea relaciones de isomorfismos (o paramorfismos) entre distintos niveles de descripción del signo traducido. La idea aquí está basada en el concepto operacional del icono, capaz de revelar la forma definida en una relación. Ejemplifico, al final, mi argumento con un caso notable de la traducción de John Donne, por Augusto de Campos. 